\title{
AVALIAÇÃO DA EFICÁCIA DO PRÉ-CONDICIONAMENTO NO RETALHO INTERÓSSEO POSTERIOR NA PREVENÇÃO DA CONGESTÃ̃ TECIDUAL
}

\author{
Ricardo Ramos Daoud Yacoub (IC), João Carlos Nakamoto (PQ), Maurício Etchebehere (PQ)
}

\section{Resumo}

A necrose do tecido fáscio-cutâneo após cirurgia plástica reconstrutiva é o evento mais preocupante no pós operatório. A morte tecidual ocorre pelo fenômeno conhecido por lesão induzida pela isquemia-reperfusão. Nesse sentido, no intuito de prevenir a perda tecidual após cirurgias de transposição de retalhos fásciocutâneos, foi estudada a técnica de pré-condicionamento por meio de um garrote pneumático que induz uma isquemia temporária pré-cirurgia.

Palavras Chave: Pré-condicionamento em humanos; isquemia-reperfusão; retalho interósseo posterior.

\section{Introdução}

A falta de circulação sanguínea leva à hipóxia e à morte celular. Porém, também se verificou em estudos que a rápida reperfusão sanguínea causa danos irreversíveis ao tecido. O précondicionamento por meio de períodos curtos de isquemia seguidos de reperfusão pode diminuir 0 dano de isquemia-reperfusão (IR) (1) que é uma das causas de necrose de tecidos em cirurgias reconstrutivas baseadas no transplante de retalhos fáscio-cutâneo

\section{Resultados e Discussão}

O estudo ainda está em andamento, por isso, os resultados são parciais. O pré-condicionamento realizado em 3 pacientes, 24h antes da cirurgia, teve como resultado final nenhuma área de necrose, e portanto, não houve necessidade de nenhuma intervenção cirúrgica secundária. Da mesma forma, não houve complicações decorrentes do pré-condicionamento. Todos os pacientes ficaram satisfeitos com o pós-cirúrgico.
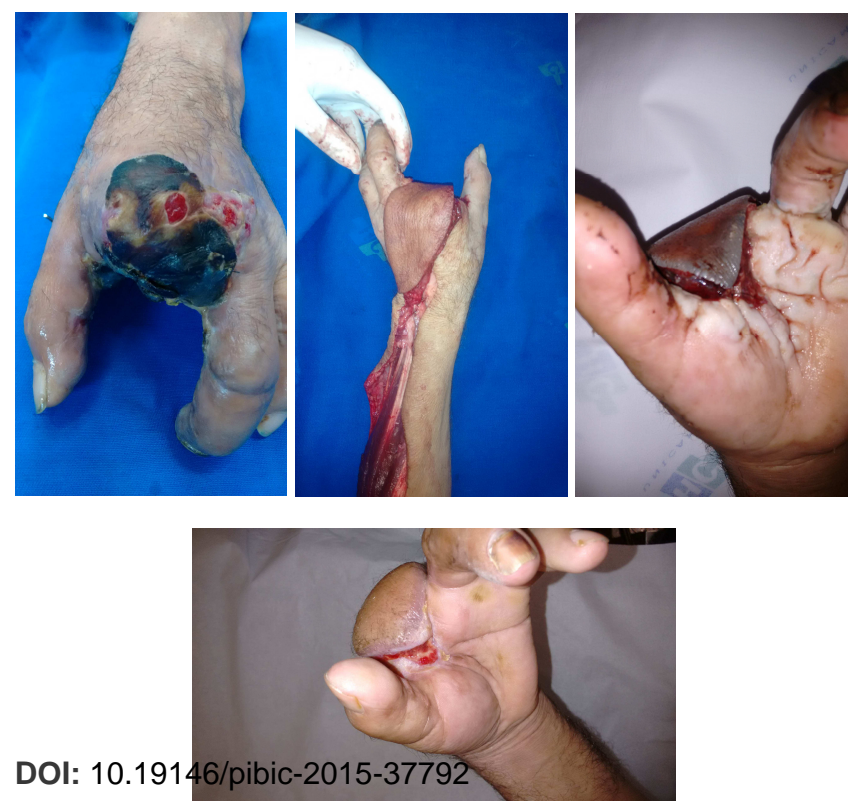

Tabela 1. Progressão da área isquêmica

\begin{tabular}{cccccc}
\hline Ident & $\begin{array}{c}\text { Área } \\
\text { Total } \\
\mathbf{c m}^{2}\end{array}$ & $\begin{array}{c}\text { Área } \\
\mathbf{3} \\
\text { dias }\end{array}$ & $\begin{array}{c}\text { Área } \\
\mathbf{7} \\
\text { dias }\end{array}$ & $\begin{array}{c}\text { Área } \\
\mathbf{2 1} \\
\text { dias }\end{array}$ & $\begin{array}{c}\text { Área } \\
\mathbf{2 8} \\
\text { dias }\end{array}$ \\
\hline AFMN & 23,7 & 0 & 0 & 0 & 0 \\
\hline AMS & 62,5 & 9,5 & 7,5 & 3 & 0 \\
\hline KAS & 21,0 & 2,5 & 1 & 0 & 0 \\
\hline
\end{tabular}

\section{Conclusões}

Ainda não é possível chegar a nenhuma conclusão definitiva devido ao número de pacientes que obtivemos. Porém, é possível dizer que o pré-condicionamento feito através de um garrote pneumático $24 \mathrm{~h}$ antes da cirurgia é uma técnica viável e que não traz nenhuma comorbidade para o paciente. Além disso, até o presente momento, os resultados obtidos com essa técnica são positivos.

\section{Agradecimentos}

\section{Agradeço o apoio do CNPq ao projeto.}

${ }^{1}$ Barker JH, Frank J, Bidiwala SB, Stengel CK, Carroll SM, Carroll CM et al. Br J Plast Surg. 1999; 52 (2): 133-42. 